\title{
Protocolo de Prevenção de Infeções Relacionadas com o Tratamento de Neoplasias Hematológicas
}

\author{
Protocol for the Prevention of Infections Related to the \\ Treatment of Hematological Malignancies
}

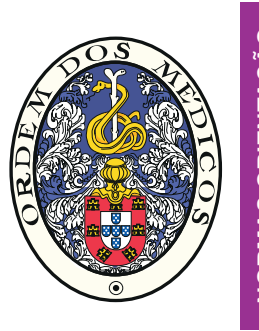

\author{
André SILVA-PINTO $\triangle^{1,2}$, Nuno ROCHA-PEREIRA ${ }^{1,2}$, Joaquim ANDRADE ${ }^{3}$, António SARMENTO ${ }^{1,2}$, Lurdes SANTOS S $^{1,2}$ \\ Acta Med Port 2018 Jun;31(6):347-361 - https://doi.org/10.20344/amp.10035
}

\begin{abstract}
RESUMO
Os doentes com doença hematológica neoplásica apresentam uma incidência de infeções superior à da população geral. Vários fatores contribuem para este aumento de incidência destacando-se os fármacos quimioterápicos que acarretam riscos infeciosos diferentes e específicos. Este protocolo versa a prevenção de infeções em doentes que vão ser submetidos a quimioterapia para tratamento de neoplasias hematológicas. Divide-se em: estudo prévio ao início de quimioterapia; vacinação e erradicações prévias ao início de quimioterapia; profilaxias antimicrobianas durante a quimioterapia; situações especiais. Pretende-se com este protocolo uma abordagem sistematizada e individualizada da situação clínica de cada doente de forma a prevenir de forma a prevenir de infeções em doentes sob quimioterapia para tratamento de neoplasias hematológicas.
\end{abstract}

Palavras-chave: Infecções Bacterianas/prevenção e controlo; Infecções Comunitárias Adquiridas/prevenção e controlo; Neoplasias Hematológicas/quimioterapia

\section{ABSTRACT}

Patients with haematological malignancies have a higher incidence of infection compared with the general population. Several factors contribute to this but specially chemotherapy drugs carry different and specific infectious risks. This protocol discusses the prevention of infections in patients who will undergo chemotherapy for the treatment of haematological malignancies. It is divided into: study prior to the initiation of chemotherapy; vaccination and eradication prior to initiation of chemotherapy; antimicrobial prophylaxis during chemotherapy; special situations. The main aims of this protocol are to serve as support to a more systematic and individualized approach to patients undergoing chemotherapy for the treatment of haematological malignancies and by doing so prevent the infectious complications that may arise.

Keywords: Bacterial Infections/prevention \& control; Community-Acquired Infections/prevention \& control; Hematologic Neoplasms/ drug therapy

\section{INTRODUÇÃO}

Os doentes com doença hematológica neoplásica têm uma taxa de incidência de infeções superior à da população geral. ${ }^{1}$ Os fatores que contribuem para este aumento da taxa de infeções são, entre outros, a alteração da função linfocitária, a supressão da função normal do plasmócito, a hipogamaglobulinemia e os efeitos secundários decorrentes da quimioterapia. ${ }^{1,2}$ Para além disto, atualmente existem cada vez mais terapêuticas dirigidas que envolvem vias ou células diretamente envolvidas na patofisiologia das doenças hematológicas e, por isso, com riscos infeciosos muito diferentes e específicos. O risco de infeção depende de diversos fatores tais como a idade, a carga tumoral, o esquema e a intensidade da quimioterapia, a duração da neutropenia, o grau de mucosite associada e as comorbilidades do doente. ${ }^{3}$

Posto isto, torna-se fundamental uma avaliação sistematizada destes doentes de modo a reduzir o número de infeções. Para além disso, a abordagem destes doentes deverá ser também sempre individualizada, pois também depende de fatores como a história passada de infeções e o status do tratamento (näive ou com experiência prévia).

Este protocolo versa sobre a prevenção de infeções em doentes hematológicos sob quimioterapia, excluindo-se a prevenção no contexto de transplantação de progenitores hematopoiéticos.

\section{MATERIAL E MÉTODOS}

Este protocolo foi elaborado entre setembro de 2017 e abril de 2018 e resulta de uma iniciativa conjunta dos serviços de Hematologia Clínica e Doenças Infeciosas do Centro Hospitalar São João.

Foi subdividido nas seguintes secções: estudo inicial prévio à quimioterapia; vacinação e erradicação prévia à quimioterapia; profilaxias antimicrobianas durante a quimioterapia; situações especiais.

A secção 'Estudo inicial prévio à quimioterapia' resulta de uma revisão da prática médica realizada no Serviço de Doenças Infeciosas.

Para elaboração da secção 'Vacinação e erradicação prévia à quimioterapia' foi revisto o Plano Nacional de Vacinação Português, as normas da Direção-Geral de Saúde sobre vacinação, as seções sobre vacinação da plataforma online UpToDate ${ }^{\circledR}$, o manual de tuberculose e micobactérias não tuberculosas da Direção-Geral da Saúde e as

1. Serviço de Doenças Infeciosas. Centro Hospitalar São João. Porto. Portugal.

2. Grupo I\&D em Nefrologia e Doenças Infeciosas. I3S - Instituto de Investigação e Inovação em Saúde. Universidade do Porto. Porto. Portugal.

3. Serviço de Hematologia Clínica. Centro Hospitalar São João. Porto. Portugal.

$\triangle$ Autor correspondente: André Silva-Pinto. pintoandre@gmail.com

Recebido: 06 de dezembro de 2017 - Aceite: 09 de maio de 2018 | Copyright @ Ordem dos Médicos 2018 
normas europeias de sífilis. Pontualmente, para colmatar dúvidas específicas, foi realizada pesquisa na MEDLINE (National Library of Medicine, Bethesda, Estados Unidos da América).

A pesquisa bibliográfica que conduziu à elaboração da secção 'Profilaxia antimicrobianas durante a quimioterapia' foi realizada na MEDLINE, utilizando termos $\mathrm{MeSH}$ que se referissem a cada agente descrito e incluindo o termo 'infeção'. Foram incluídos artigos na língua inglesa, sem restrição temporal. Foram também revistos os resumos das características dos medicamentos (RCM) dos fármacos em questão, os alertas da agência europeia do medicamento (European Medicines Agency - EMA) e da Food and Drug Administration (FDA) e as revisões de literatura já existentes sobre infeção nos doentes hematológicos. Foram ainda acrescentados outros artigos considerados de interesse por pesquisa nas referências dos artigos previamente incluídos.

A secção 'Situações especiais' refere-se a doentes com contexto epidemiológico relevante no estrangeiro. Foi feita uma pesquisa na MEDLINE sobre os agentes infeciosos considerados mais importantes.

O protocolo foi difundido pelos médicos dos serviços de Doenças Infeciosas e Hematologia Clínica e, posteriormente, discutido em reuniões de serviço.

\section{ESTUDO INICIAL PRÉVIO AO INÍCIO DE QUIMIOTERAPIA}

No estudo inicial de um doente com neoplasia hematológica que vai iniciar quimioterapia deve estar incluída uma história clínica completa que inclua os seguintes pontos:

- História médica passada

- Doenças da infância

- Doenças crónicas

- Hospitalizações

- Cirurgias

- História epidemiológica

- Tipo de habitação e condições de habitabilidade

- Contacto com animais

- Contacto com zonas arborizadas

- Consumo de água não potável

- Consumo de leite não pasteurizado

- Viagens

- Contacto com pessoas doentes (incluindo com tuberculose)

- História profissional

Para além da história clínica, o seguinte estudo é aconselhado:

- Serologia para vírus citomegálico (CMV)

- Serologia para vírus Epstein Barr (EBV)

- Serologia para vírus Herpes Simplex (HSV) 1 e 2

- Serologia para vírus Varicella Zoster (VZV)

- Serologia para Toxoplasmose

- Serologia para vírus da Hepatite A (VHA): pesquisa de imunoglobulina $\mathrm{G}(\lg \mathrm{G})$

- Serologia para vírus da Hepatite B (VHB): antigénio de superfície (AgHBs), anticorpo de superfície (AcHBs) e anticorpo do core (AcHBc)

- No caso de AgHBs positivo: carga vírica de VHB, antigénio 'e' (AgHBe) e anticorpo 'e' (AcHBe)

- No caso de AcHBc positivo com AgHBs negativo: carga vírica de VHB (por técnica de PCR)

- Serologia para vírus da Hepatite C (VHC)

- No caso de anti-VHC positivo: carga vírica de VHC - Serologia para vírus da Hepatite E (VHE): pesquisa de imunoglobulina G (lgG)

- Serologia para vírus da imunodeficiência humana

$(\mathrm{VIH})$

- Serologia para Parvovirus B19

- Rastreio serológico da sífilis (teste treponémico e não treponémico)

- Rastreio de tuberculose latente ${ }^{4}$

- Radiograma do tórax

- Interferon Gamma Release Assay (IGRA)

- Prova de Mantoux

- Serologia para Leishmania spp. (a ser ponderada de acordo com o contexto epidemiológico do doente)

- Regiões em Portugal com maior endemicidade: Alto Douro, Região de Lisboa e Algarve ${ }^{5}$

\section{VACINAÇÃO E ERRADICAÇÃO PRÉVIAS AO INÍCIO DE QUIMIOTERAPIA \\ Vacinação no imunodeprimido}

Em relação à vacinação no imunodeprimido:

- As vacinas vivas (como por exemplo vacina anti sarampo, parotidite e rubéola, vacina contra a varicela, vacina contra a febre amarela ou BCG) não devem ser administradas a doentes imunodeprimidos nem nos quais se prevê imunossupressão no período de 4 semanas após vacinação (risco de doença induzida pela vacina). Após quimioterapia, o período em que não devem ser administradas vacinas vivas varia com a terapêutica efetuada, sendo geralmente três meses, ou seis meses se anticorpos anti células $B .^{6}$

- As vacinas vivas, se administradas, deverão ser administradas no mesmo dia ou então separadas por quatro semanas. A prova tuberculínica também deverá ser realizada no mesmo dia de administração de uma vacina viva ou então separada por quatro semanas. ${ }^{6}$

- As vacinas inativadas podem ser administradas com segurança nos doentes sob quimioterapia, embora a sua imunogenicidade esteja diminuída nos doentes imunodeprimidos. ${ }^{6}$

- A vacinação deve ser realizada, idealmente, pelo menos 10 a 14 dias antes do início da quimioterapia. ${ }^{6,7}$

- Na impossibilidade de fazer previamente à quimioterapia, a vacinação não deverá ser administrada no mesmo dia que a quimioterapia ou numa altura de imunossupressão profunda, mas entre os ciclos de quimioterapia de forma a obter uma maior proteção (apesar de não existir nenhuma contraindicação à vacinação). ${ }^{8}$ - Vacinação durante a quimioterapia e até três meses após conclusão da quimioterapia (ou seis meses 
se anticorpos anti-células B) é menos imunogénica. Se a vacinação for administrada num período de menor imunogenecidade, deve-se considerar uma dose extra três meses após a conclusão da quimioterapia ou 6 meses após se administração de anticorpos anti-células B. 7,8

A Tabela 1 pretende resumir quais as vacinas inativadas [pertencente ao Plano Nacional de Vacinação (PNV) e extra-PNV] que se podem administrar aos doentes com neoplasia hematológica, assim como os seus esquemas de administração. 6,9

As vacinas vivas e as vacinas relacionadas com viagens, por não se poderem administrar a doentes imunodeprimidos ou se administrarem em situações muito específicas não foram consideradas neste protocolo.

\section{Vacinação recomendada no doente com neoplasia he- matológica}

No doente com neoplasia hematológica, deve-se verificar sempre a vacinação prévia.

Recomendam-se a realização das seguintes vacinas ${ }^{6,8}$ :

- Vacinação contra VHA se ausência de vacinação prévia e serologia negativa; no caso de não resposta à vacina pode-se fazer uma dose de reforço;

- Vacinação contra VHB se ausência de vacinação prévia e serologia (AcHBs, AcHBc e AgHBs) negativa; no caso de não resposta à vacina pode-se fazer um novo ciclo de vacinação (a avaliação de resposta à vacinação deve ser feita 1 a 2 meses após completar ciclo de vacinação);

- Vacinação contra gripe todos os anos na altura do inverno;

- Vacinação contra Streptococcus pneumoniae com vacina polisacarídica conjugada 13-valente e, se possível, vacina polisacarídica 23-valente (respeitando os períodos de intervalo mínimos entre vacinas).
Especificidades sobre vacinas recomendadas no doente com neoplasia hematológica

- Vacinação contra o VHA:

- Os doentes sem história de vacinação contra o VHA e com serologia negativa para o VHA, deverão fazer a vacina (duas doses separadas por 6 a 12 meses);

- Se tiverem sido vacinados previamente contra o VHA, mas o título de anticorpos for negativo, deverão fazer um reforço de VHA. ${ }^{10}$

- Vacinação contra o VHB:

- Os doentes sem história de vacinação contra o VHB e com serologia negativa para o VHB (AgHBs, AcHBs e AcHBc negativos), deverão fazer a vacina (três doses no esquema 0, 1 e 6 meses); esquema acelerado: 0, 7, 21 dias (e reforço após um ano);

- Na necessidade de fazer vacina contra VHA e VHB, poderão fazer a vacinação conjunta (Twinrix ${ }^{\circledR}$ : esquema 0,1 e 6 meses); esquema acelerado: 0, 7, 21 dias (e reforço após 1 ano);

- Se tiverem sido vacinados previamente contra o $\mathrm{VHB}$, mas o título de AcHBs for inferior a $10 \mathrm{UI} / \mathrm{mL}$, deverão fazer um reforço de vacina (1 dose antes da imunossupressão) e avaliação de resposta 1 a 2 meses após reforço vacinal. ${ }^{6,8,11}$ Se ausência de resposta pode tentar fazer-se novo ciclo vacinal completa (3 doses).

- Vacinação contra a gripe:

- A vacinação contra a gripe deverá ser realizada todos os anos, na altura do inverno. ${ }^{8}$

- Vacinação contra o Streptococcus pneumoniae:

- Na ausência de vacinação prévia contra o S. pneumoniae $\rightarrow$ vacina polissacarídica conjugada 13-valente prévia à quimioterapia. A vacina polissacarídica 23-valente poderá ser realizada oito semanas após;

Tabela 1 - Vacinas inativadas e esquemas de administração que se podem administrar aos doentes com neoplasia hematológica

\begin{tabular}{|c|c|c|c|}
\hline \multicolumn{2}{|l|}{ Vacina } & $\begin{array}{l}\text { Neoplasia sob } \\
\text { quimioterapia }\end{array}$ & Esquema de administração \\
\hline \multicolumn{4}{|c|}{ Vacinas Inativadas Comuns } \\
\hline \multirow{4}{*}{ PNV } & VHB & $\operatorname{sim}$ & $\begin{array}{l}3 \text { doses: } 0,1 \text { e } 6 \text { meses } \\
\text { Esquema rápido: } 0,7,21 \text { dias e } 1 \text { ano }\end{array}$ \\
\hline & Td, Tdpa & $\operatorname{sim}$ & 1 em cada $10-20$ anos \\
\hline & Poliomielite (inativada) & $\operatorname{sim}$ & 3 doses: 0,1 e 12 meses \\
\hline & Meningocócica & $\operatorname{sim}$ & $\begin{array}{l}\text { Conjugada grupo } \mathrm{C}-1 \text { dose } \\
\text { Conjugadas grupos } \mathrm{A}, \mathrm{C}, \mathrm{Y}, \mathrm{W}-1 \text { dose (até } 55 \text { anos); depois dos } 56 \\
\text { anos pode fazer a polissacarídica não conjugada } \\
\text { Grupo B - } 2 \text { doses separadas por pelo menos } 1 \text { mês (até } 50 \text { anos) }\end{array}$ \\
\hline \multirow{4}{*}{ Extra-PNV } & VHA & $\operatorname{sim}$ & 2 doses: 0 e 6 - 12 meses \\
\hline & Gripe (inativada) & $\operatorname{sim}$ & Anual \\
\hline & $\begin{array}{l}\text { Pneumocócica } \\
\text { conjugada } 13 \text { valente }\end{array}$ & $\operatorname{sim}$ & $\begin{array}{l}1 \text { dose (idealmente antes da } 23 \text { valente); realizar após } 1 \text { ano da } 23 \\
\text { valente }\end{array}$ \\
\hline & $\begin{array}{l}\text { Pneumocócica } \\
\text { polisacarídica } 23 \text { valente }\end{array}$ & $\operatorname{sim}$ & $\begin{array}{l}1 \text { dose (idealmente após a } 13 \text { valente); reforço após } 5 \text { anos ( } 1 \\
\text { reforço antes e } 1 \text { depois dos } 65 \text { anos); realizar } 8 \text { semanas após } 13 \\
\text { valente }\end{array}$ \\
\hline
\end{tabular}


- No caso de vacinação prévia com vacina polissacarídica conjugada 13-valente $\rightarrow$ vacina polissacarídica 23-valente desde que tenham decorrido mais de oito semanas desde a vacina polissacarídica conjugada 13-valente;

- No caso de vacinação prévia com vacina polissacarídica 23-valente $\rightarrow$ vacina polissacarídica conjugada 13-valente desde que tenham decorrido mais de um ano desde a vacina polissacarídica 23-valente;

- No caso de vacinação prévia com vacina polissacarídica conjugada 13-valente e vacina polissacarídica 23-valente $\rightarrow$ vacina polissacarídica 23-valente desde que tenha decorrido mais de cinco anos desde a vacina polissacarídica 23-valente e oito semanas desde a vacina polissacarídica conjugada 13-valente ${ }^{7}$

- Em relacão aos reforcos vacinais de vacina polissacarídica 23-valente, os doentes deverão fazer um reforço até aos 65 anos e outro reforço depois dos 65 anos (tendo em conta que o tempo mínimo entre as doses de vacina polissacarídica 23-valente é cinco anos). ${ }^{12}$

- Vacinação contra a Poliomielite:

- Se pelo menos três doses de VIP $\rightarrow$ sem necessidade de reforço (exceto se viagem para zona endémica de poliomielite);

- Se menos que três doses de VIP $\rightarrow$ fazer ou completar esquema de três doses (esquema recomendado: 0, 1, 7-13 meses; esquema acelerado: 0, 1, 2 meses, com reforço após 1 ano). ${ }^{6}$

- Vacinação contra o meningococo:

- Em situações específicas (deslocações frequentes a África incluindo 'cinturão da meningite', défice de anticorpos, tratamento com eculizumab ${ }^{\circledR}$, asplenia anatómica ou funcional e défice de complemento) pode-se ponderar a vacina conjugada quadrivalente contra serogrupo A, C, Y e W $\left(\right.$ Menveo $\left.^{\circledR}\right){ }^{8}$

- A vacina contra o serogrupo B $\left(\right.$ Bexsero $\left.^{\circledR}\right)$ deve ser considerada em doentes de alto risco tais como: deficiência persistente do complemento, tratamento com inibidores do complemento (eculizumab ${ }^{\circledR}$ ) ou doente com asplenia funcional ou anatómica. ${ }^{13}$

- Nota: Existem múltiplas patologias associadas com hiposplenia, incluindo as leucemias agudas e as doenças mieloproliferativas crónicas. Na suspeita de asplenia funcional, a função esplénica deve ser avaliada por técnicas apropriadas (deteção de corpos de Howell-Jolly, ecografia abdominal ou TC abdominal para documentar redução do tamanho esplénico, cintigrafia de glóbulos vermelhos). ${ }^{14,15}$

\section{Erradicação recomendada no doente com neoplasia hematológica \\ - Tuberculose latente}

- O rastreio de tuberculose latente deve ser realizado em todos os doentes com neoplasia hematoló- gica previamente à realização de quimioterapia ${ }^{16,17}$; - Pressupostos: excluída tuberculose ativa (pelo inquérito de sintomas e radiograma de tórax) e sem tratamento de tuberculose prévio;

- Exames a realizar: radiograma do tórax, IGRA e prova tuberculínica;

- Diagnóstico: IGRA positivo ou prova tuberculínica positiva (cut-off: $5 \mathrm{~mm}$ ) ou radiograma do tórax com evidência de tuberculose ou antecedentes de tuberculose pregressa não tratada;

- Tratamento: isoniazida $5 \mathrm{mg} / \mathrm{kg} / \mathrm{dia}$ (máximo 300 $\mathrm{mg}$ ) durante 6 - 9 meses;

- Quando iniciar quimioterapia: idealmente um mês após início de isoniazida, mas, dependendo da urgência de iniciar quimioterapia, pode começar antes (o risco de toxicidade cruzada e de reativação de tuberculose latente é, contudo, maior). ${ }^{4}$

- Sífilis

- A quem fazer tratamento: rastreio serológico positivo e sem tratamento prévio ou com risco de re-exposição;

- Tratamento: sífilis precoce - penicilina G benzatínica 2.4 MU toma única; sífilis tardia - penicilina G benzatínica 2.4 MU semanal em três semanas seguidas;

- Quando iniciar quimioterapia: após a primeira toma de penicilina $\mathrm{G}$ benzatínica. ${ }^{18}$

\section{PROFILAXIAS ANTIMICROBIANAS DURANTE A QUIMIOTERAPIA}

Tipos de profilaxia antimicrobiana

\section{Profilaxia antibacteriana}

A profilaxia antibacteriana consiste na utilização de antibacteriano ativo contra bacilos Gram negativo (incluindo Pseudomonas aeruginosa) e Streptococcus viridans durante o período de neutropenia consequente da quimioterapia. O fármaco mais extensivamente estudado é a levofloxacina. ${ }^{19}$ Várias normas internacionais recomendam esta profilaxia mas apenas nas neutropenias de alto risco, isto é, se contagem de neutrófilos inferior a $100 / \mathrm{mL}$ por tempo previsto superior a sete dias (na prática, na quimioterapia das leucemias agudas). ${ }^{20,21}$

Sobre esta temática devemos considerar o seguinte:

- Em termos de redução de mortalidade, os estudos são inconsistentes (alguns mostram redução da mortalidade, outros não demonstram efeito) e uma meta-análise de ensaios clínicos aleatorizados não conseguiu mostrar diferença estatisticamente significativa ${ }^{22}$;

- A eficácia da profilaxia está comprometida quando a taxa de resistências às quinolonas dos bacilos Gram negativos é superior a $20 \% .{ }^{23,24}$ Os estudos com profilaxia em locais com altas taxas de resistência às quinolonas, não mostrou diferenças na mortalidade ou na incidência de febre ${ }^{25}$;

- Segundo os dados de 2016 do European Centre for Diseases Control, em Portugal a taxa de resistência às quinolonas da $E$. coli, K. pneumoniae e $P$. aeruginosa é 
de $28,9 \%, 41,7 \%$ e $20,1 \%$, respetivamente (amostras invasivas);

- A profilaxia está associada a um aumento da taxa de resistência aos antibacterianos (quer de bacilos Gram negativo quer de cocos Gram positivo). ${ }^{26}$

Tendo em conta o exposto anteriormente, consideramos que a profilaxia antibacteriana não deverá ser utilizada por rotina, mesmo nos doentes com leucemia aguda sob quimioterapia (neutropenia profunda por tempo previsto superior a sete dias). Poderá ser ponderado em casos muito específicos quando a equipa assistente considerar que o benefício suplanta o risco (exemplos: comorbilidades graves, antecedentes de enterocolite neutropénica grave, aloimunização plaquetária com trombocitopenia grave refratária).

Caso seja necessário, a profilaxia pode ser realizada com levofloxacina $500 \mathrm{mg}$ PO id durante o período de maior imunossupressão. ${ }^{20}$

É importante ressalvar que em termos de prevenção de infeção não deverão ser descuradas as precauções padrão (incluindo a higienização das mãos), em todos os doentes, e as precauções de isolamento, quando indicado. ${ }^{27}$

\section{Profilaxia antifúngica}

As infeções fúngicas invasivas ocorrem com frequência aumentada nos doentes com neoplasia hematológica, estando estas infeções relacionadas com a duração e profundidade da neutropenia, a utilização de antibacteriano por períodos prolongados e o número de ciclos de quimioterapia. ${ }^{28}$ Apesar da incidência aumentada de infeções fúngicas nos doentes com neoplasia hematológica, fatores como a toxicidade, o aparecimento crescente de resistências e o custo também devem ser tidos em conta e, por isso, a profilaxia antifúngica deve ser cuidadosamente selecionada só para alguns doentes.

A profilaxia antifúngica pode ser feita apenas contra fungos leveduriformes (essencialmente Candida spp.) ou contra fungos leveduriformes e filamentosos (essencialmente Candida spp. e Aspergillus spp.):

- Profilaxia contra fungos leveduriformes: $1^{\mathrm{a}}$ linha - Fluconazol 400 mg PO uma vez por dia (qd); alternativa micafungina $50 \mathrm{mg}$ EV qd ou anfotericina B lipossómica $5 \mathrm{mg} / \mathrm{kg}$ EV duas vezes por semana ${ }^{20}$;

- Profilaxia contra fungos leveduriformes e filamentosos: $1^{a}$ linha - Posaconazol 300 mg qd PO (comprimidos); alternativa - posaconazol $200 \mathrm{mg}$ três vezes por dia (tid) PO (solução oral) ou micafungina 50 mg EV qd ou anfotericina B lipossómica $5 \mathrm{mg} / \mathrm{kg}$ duas vezes por semana. ${ }^{20}$

As indicações para profilaxia primária são as seguintes: - Profilaxia contra fungos leveduriformes: leucemia linfóide aguda (LLA), LMA promielocítica, linfomas com quimioterapia intensiva (associado a neutropenia profunda por mais de sete dias com mucosite grave) ou associação de análogos das purinas, anti-CD52 e corticóide;
- Profilaxia contra fungos leveduriformes e filamentosos: apenas deve ser realizada em situações muito específicas como neutropenia de alto risco na leucemia mielóide aguda (LMA) e síndrome mielodisplásico (SMD) avançado. ${ }^{20,29,30}$

- Duração: durante o período de neutropenia e até à sua resolução (neutrófilos superiores a 500/ $\mathrm{LL}$ ). ${ }^{28}$

Os doentes com história prévia de aspergilose invasiva e que vão ser sujeitos a quimioterapia mielossupressiva com neutropenia profunda por um tempo previsível longo, poderão ser candidatos a profilaxia secundária.

Notas:

- Quando a profilaxia é realizada com posaconazol solução oral, deverão ser monitorizados os seus níveis sanguíneos (5 - 7 dias após início) devido à grande variabilidade de absorção com o conteúdo lípido da refeição ingerida e com o $\mathrm{pH}$ gástrico. ${ }^{20}$

- Os triazóis estão associados a múltiplas interações medicamentosas (por exemplo com vincristina), devido às alterações das vias enzimáticas hepáticas $\rightarrow$ antes de se iniciar profilaxia deverão ser revistas todas as possíveis interações. ${ }^{20}$

\section{Profilaxia de pneumocistose (PPC)}

A profilaxia de PPC está preconizada nas seguintes situações:

- LLA $\rightarrow$ durante a quimioterapia ${ }^{20}$;

- Tratamento com anti-CD52 $\rightarrow$ até pelo menos dois meses após paragem do tratamento e recuperação imunológica com contagem de linfócitos CD4 superior a $200 / \mathrm{mm}^{3} 20$;

- Tratamento de combinação de análogos das purinas com outros agentes depletores de células $T$, ciclofosfamida ou anti-CD20 $\rightarrow$ até paragem do fármaco e recuperação imunológica com contagem de linfócitos CD4 superior a $200 / \mathrm{mm}^{3}$ 20,31,32;

- Tratamento com inibidores do fosfatidilinositol-3-cínase; tratamentos prolongados com corticosteróide (superior a quatro semanas com doses superiores ao equivalente de $20 \mathrm{mg}$ de prednisolona diária); tratamento com inibidores do m-TOR; tratamento com anti-CD19; tratamento com inibidor da Janus cínase (JAK) 1/2 $\rightarrow$

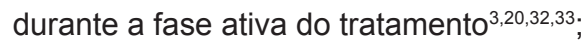

- Tratamento com inibidores da tirosina cínase de Bruton (Bruton's tyrosine kinase - BTK) $\rightarrow$ pode ser ponderada, especialmente se fatores de risco adicionais para PPC (outros depletores de células T). ${ }^{34}$

Primeira linha: TMP/SMX 960 mg PO três vezes por semana ou TMP/SMX 480 mg PO qd.

Alternativas: atovaquona 1500 mg qd ou dapsona 100 $\mathrm{mg} \mathrm{qd.}{ }^{20}$

No caso de alergia ao TMP/SMX, deve ser considerada a dessensibilização (realizada em consultadoria com a imunoalergologia).

Se tratamento com dapsona, deverá ser feito doseamento de glicose 6-fosfato desidrogenase previamente. 
Profilaxia anti-virus herpes simplex/varicella zoster

A profilaxia contra reativação de VZV e HSV deverá ser feita apenas se serologia positiva para algum dos vírus (vírus herpes simplex 1 (HSV1), vírus herpes simplex 2 (HSV2) ou vírus varicella zoster (VZV)).

A profilaxia contra reativação de VZV e HSV pode ser considerada durante a fase ativa de quimioterapia de neoplasias hematológicas como linfomas, mieloma múltiplo e LLC, especialmente se associadas com neutropenia prolongada, receberem altas doses de corticosteróides ou agentes depletores de células T. É, contudo, defensável não fazer profilaxia em alguns casos de monoterapia. ${ }^{20}$

Nos casos de leucemias agudas, a profilaxia deverá ser realizada sempre durante o período de quimioterapia ativa e de neutropenia (HSV). ${ }^{20}$

No caso de tratamento com lenalidomida/pomalidomida recomenda-se profilaxia durante a fase de quimioterapia ativa e neutropenia, especialmente se associado a outros imunossupressores ou se idade avançada (VZV). ${ }^{29}$

No caso de utilização de anti-CD52, deverá ser feita profilaxia até dois meses após paragem do fármaco e recuperação imunológica com CD4 superiores a $200 / \mathrm{mm}^{3}$ (HSV e VZV). ${ }^{20}$

No caso de utilização de anti-CD38 e anti-SLAMF7 deverá ser feita profilaxia que se inicia uma semana antes de começar anti-CD38/anti-SLAMF7 e continua até três meses após paragem do anti-CD38/anti-SLAMF7 (VZV). ${ }^{1,35}$

No caso de utilização de inibidores de proteossoma, inibidores do m-TOR, inibidores da JAK 1/2 e anti-CD19 deverá sempre ser feita profilaxia durante o período de quimioterapia ativa e de neutropenia (VZV). ${ }^{1,3,33,36}$

Se houver reativação do HSV ou VZV durante a quimioterapia, recomenda-se sempre a profilaxia em ciclos futuros de quimioterapia. ${ }^{20}$

Primeira linha: valaciclovir 500 mg duas vezes por dia (bid); Alternativa: aciclovir 800 mg bid, foscarnet EV 40 mg/ $\mathrm{kg}$ tid..$^{20}$

\section{Profilaxia/tratamento de antecipação anti-CMV}

A profilaxia e o tratamento de antecipação para CMV deverão ser ponderadas apenas se serologia para o CMV positiva ( $\operatorname{lgG}) .^{20,36}$

Nos doentes tratados com anti-CD52, a reativação de CMV ocorre mais frequentemente entre as 3 e 6 semanas após início do fármaco (período de nadir de linfócitos T). ${ }^{20}$ Em relação ao tratamento anti-CMV nos doentes tratados com anti-CD52 podem-se adotar duas estratégias diferentes:

- Tratamento de antecipação: estratégia preferencial, especialmente na monoterapia com anti-CD52; monitorização semanal com carga vírica do CMV (por técnica de biologia molecular - polymerase chain reaction (PCR) quantitativo em tempo real) no sangue até pelo menos dois meses após paragem do fármaco e reconstituição imunológica com contagem de CD4 superior a $100 / \mathrm{mm}^{3}$; no caso de carga vírica positiva (definido como PCR positivo em mais de duas amostras conse- cutivas separadas por uma semana), pode-se optar por iniciar terapêutica ou monitorizar, dependendo da apresentação clínica, do valor da carga vírica e do projeto terapêutico (decisão caso a caso); o tratamento deverá ser feito sem interrupção do anti-CD52 ${ }^{20,29}$;

- Profilaxia - ponderar no caso de tratamentos de combinação com anti-CD52 (especialmente se junção de vários agentes depletores de células $\mathrm{T}$ ); iniciar o fármaco quando inicia a quimioterapia; a profilaxia deverá ser mantida até pelo menos dois meses após paragem da quimioterapia e reconstituição imunológica com contagem CD4 superior a $100 / \mathrm{mm}^{3}{ }^{3} \cdot 2,37$

No caso de tratamento com inibidor de JAK1/2 e inibidores do fosfatidilinositol-3-cínase (PI3K), também se preconiza uma estratégia de antecipação com monitorização do PCR do CMV a cada três meses e inicio de terapêutica se reativação de $\mathrm{CMV} .^{34,36}$

Primeira linha: Profilaxia - valganciclovir 900 mg PO qd; Tratamento de antecipação - indução com valganciclovir 900 mg PO bid durante pelo menos duas semanas (e com negativação da carga vírica); manutenção com valganciclovir $900 \mathrm{mg}$ PO qd durante pelo menos sete dias após negativação de carga vírica.

Alternativas: ganciclovir EV $5 \mathrm{mg} / \mathrm{kg}$ bid; foscarnet EV $60 \mathrm{mg} / \mathrm{kg}$ tid; cidofovir EV $5 \mathrm{mg} / \mathrm{kg}$ semanal. ${ }^{20,29}$

Nota: nos doentes com profilaxia de CMV, não é necessário fazer aciclovir/valaciclovir para profilaxia de HSVIVZV (o valganciclovir é ativo contra os três vírus). ${ }^{29}$

\section{Tratamento e profilaxia de reativação do VHB}

Os doentes com AgHBs positivo e que ainda não estão sob tratamento, deverão ter quantificação da carga vírica do VHB por PCR e iniciar tratamento previamente ao início de quimioterapia. ${ }^{20,38,39}$

$\mathrm{Na}$ presença de AcHBc e AcHBs (infeção passada), recomenda-se monitorizar carga vírica do VHB (por PCR), se alteração de transamínases durante a quimioterapia. Se AcHBc positivo e AgHBs e AcHBs negativos (possível infeção oculta), deverá realizar-se a carga vírica do VHB (por $\mathrm{PCR}$ ). Se carga vírica positiva, deverá ser realizado tratamento semelhante aos doentes com AgHBs positivo. ${ }^{38,39} \mathrm{Se}$ carga vírica negativa, esta deverá ser monitorizada mensalmente durante o período de imunossupressão (ou mais precocemente se elevação das transamínases). ${ }^{34}$

No caso de hepatite $B$ crónica prévia à imunossupressão, o doente deverá continuar a fazer tratamento após suspensão da quimioterapia e aplicam-se as regras de monitorização e descontinuação do tratamento do doente imunocompetente. ${ }^{38,39}$

No caso de infeção crónica por VHB sem hepatite (carga vírica VHB prévia ao tratamento detetável), recomenda-se manter a profilaxia durante pelo menos 12 meses após cessação da quimioterapia e ponderar descontinuação de tratamento anti-VHB apenas se doença de base em remissão. A monitorização da carga vírica do VHB e testes de função hepática deve ser feita cada 3 a 6 meses durante a profilaxia e até um ano após suspensão da profilaxia. ${ }^{38,39}$ 
Nos doentes sob terapêutica com anti-CD20 e anti-CD19 é necessário fazer profilaxia de reativação de VHB se AcHBc positivo [independentemente do AcHBs e AgHbs, devido à presença de ácido desoxirribonucleico (ADN) circular fechado covalentemente nos hepatócitos], com monitorização de PCR VHB mensal durante o tratamento e trimestral após conclusão do tratamento. A profilaxia deverá ser mantida até 18 meses após paragem do tratamento. $20,33,38,39$

Nos doentes sob terapêutica com inibidores do BTK, têm sido reportados na literatura vários casos de reativação de infeção oculta por VHB e mesmo de reativação de infeção passada por VHB, semelhante ao reportado com anti-CD20.40-42 Está atualmente em curso um ensaio clínico para estabelecer a segurança dos inibidores do BTK nos doentes com infeção por VHB (NCT02991638). Enquanto se aguarda pelos resultados dos estudos em curso, aconselhamos uma atitude semelhante ao realizado com os anti-CD20 (profilaxia mesmo em caso de apenas AcHBc positivo).

Primeira linha para profilaxia ou tratamento: entecavir 0,5 mg PO qd (no caso de exposição prévia à lamivudina ou teste de resistências com resistência possível ao entecavir, pode-se fazer entecavir $1 \mathrm{mg}$ PO qd) ou tenofovir disoproxil fumarato $245 \mathrm{mg} P O$ qd ou tenofovir alafenamida $25 \mathrm{mg} P O$ qd.

Alternativa: lamivudina 100 mg PO qd (nota: o risco de indução de resistências pode ser tão alto como 80\% após cinco anos de tratamento com lamivudina). ${ }^{38,39}$

\section{Profilaxia da gripe}

Em casos muito selecionados, se exposição comprovada ao vírus da gripe de um doente suscetível com neoplasia em fase ativa sob quimioterapia, pode-se ponderar a profilaxia pós-exposição com oseltamivir

Dose de profilaxia: oseltamivir PO $75 \mathrm{mg}$ qd durante sete dias. ${ }^{43}$

\section{Profilaxia contra a toxoplasmose}

A profilaxia contra reativação de Toxoplasma gondii deverá ser feita apenas se serologia positiva.

Esta profilaxia encontra-se indicada no caso de tratamento com inibidor do JAK1/2 (também com indicação para profilaxia de PPC).

Primeira linha: TMP/SMX 960 mg PO três vezes por semana ou TMP/SMX $480 \mathrm{mg} P O$ qd. ${ }^{36}$

Alternativa: atovaquona $1500 \mathrm{mg}$ qd

Nota: os doentes com profilaxia para PPC com terapêutica com TMP/SMX ou atovaquona, estão também sob profilaxia para toxoplasmose; por outro lado, os doentes a fazer dapsona para profilaxia de PPC não estão sob profilaxia para toxoplasmose, sendo necessário acrescentar pirimetamina e ácido folínico. ${ }^{44}$ Aconselha-se que nos doentes a fazer inibidor da JAK1/2, a profilaxia de PPC e toxoplasmose seja feita ao mesmo tempo para as duas patologias, com TMP/SMX ou atovaquona.

\section{Profilaxias específicas por fármaco utilizado}

A Tabela 2 pretende sistematizar os fármacos usados na quimioterapia de doentes com neoplasia hematológica, sendo apenas uma listagem indicativa e não exaustiva.

São considerados agentes depletores de células $T$ os seguintes grupos de fármacos: anti-CD52, análogos das purinas, inibidores do proteossoma, corticoterapia em dose equivalente superior a prednisolona $1 \mathrm{mg} / \mathrm{Kg} / \mathrm{dia} .{ }^{1}$

De seguida, descreve-se, por classe de fármacos, quais os seus principais efeitos a nível do sistema imunitário e quais as profilaxias recomendadas e as principais infeções associadas.

Ressalvamos que não é possível considerar todas as situações e que há algumas profilaxias e infeções que surgem da sobreposição de várias agentes quimioterápicos ao longo do tempo, das doenças prévias do doente e do estádio da neoplasia hematológica.

\section{Corticosteróides}

\section{Principais infeções: PPC, bacterianas}

Altas doses de corticosteróide (equivalente a uma dose diária superior a $20 \mathrm{mg}$ de prednisolona): efeitos graves na distribuição e função dos neutrófilos, monócitos e linfócitos.

Usados frequentemente em associação com outros fármacos.

O seu efeito depende da dose, duração, do estádio da neoplasia e do uso de outros imunossupressores.

Deve-se considerar profilaxia de PPC no caso de tratamentos prolongados (superior a quatro semanas) com doses diárias superiores a $20 \mathrm{mg}$ de prednisolona (ou equivalente). ${ }^{20,32}$

\section{Agentes alquilantes}

\section{Principais infeções: bacterianas}

Os agentes alquilantes ligam um grupo alquil ao ADN, levando à destruição do ADN e subsequente morte celular. Ligam-se às células com rápida divisão celular como as células cancerígenas, mas também do trato gastrointestinal e médula óssea, por exemplo.

A sua utilização está relacionada com aumento das infeções bacterianas

Não estão recomendadas profilaxias

\section{Análogos das purinas}

Principais infeções: PPC, VZV, HSV

Antimetabolitos que mimetizam a estrutura química das purinas.

Linfocitotóxicos, especialmente para os linfócitos $\mathrm{T}$ CD4 ${ }^{+}$.

A sua utilização está associada (especialmente quando usada em terapêutica de combinação com outros quimioterápicos depletores de células $\mathrm{T}$ ) com infeções oportunistas tais como PPC, infeções fúngicas oportunistas e infeções víricas (VZV e HSV).

$\mathrm{O}$ seu efeito sobre os linfócitos $\mathrm{T} C D 4^{+}$é prolongado no tempo, persistindo após vários meses da paragem da quimioterapia (a profilaxia deve ser mantida até seis meses 
Tabela 2 - Principais fármacos utilizados na quimioterapia de doentes com neoplasia hematológica, por grupo farmacológico

\begin{tabular}{|c|c|c|}
\hline \multirow[t]{4}{*}{ Agentes não dirigidos } & Corticosteróides & $\begin{array}{l}\text { Dexametasona } \\
\text { Metilprednisolona } \\
\text { Prednisolona }\end{array}$ \\
\hline & Agentes alquilantes & $\begin{array}{l}\text { Bendamustina } \\
\text { Ciclofosfamida } \\
\text { Clorambucil }\end{array}$ \\
\hline & Análogos das purinas & $\begin{array}{l}\text { Cladribina } \\
\text { Fludarabina } \\
\text { Pentostatina }\end{array}$ \\
\hline & Imunomoduladores & $\begin{array}{l}\text { Lenalidomida } \\
\text { Pomalidomida } \\
\text { Talidomida }\end{array}$ \\
\hline \multirow[t]{7}{*}{ Anticorpos monoclonais } & Anti-CD20 & $\begin{array}{l}\text { Ibritumomab } \\
\text { Obinutuzumab } \\
\text { Ocrelizumab } \\
\text { Ofatumumab } \\
\text { Rituximab } \\
\text { Tositumomab }\end{array}$ \\
\hline & Anti-CD52 & Alentuzumab \\
\hline & Anti-CD30 & Brentuximab vedotin \\
\hline & Anti-CD19 & $\begin{array}{l}\text { Blinatumumab } \\
\text { Inebilizumab }\end{array}$ \\
\hline & Anti-CD22 & $\begin{array}{l}\text { Epratuzumab } \\
\text { Inotuzumab } \\
\text { Moxetumomab }\end{array}$ \\
\hline & Anti-CD38 & $\begin{array}{l}\text { Daratumumab } \\
\text { Isatuximab }\end{array}$ \\
\hline & Anti-SLAMF7 & Elotuzumab \\
\hline \multirow[t]{9}{*}{ Inibidores } & Inibidores do proteossoma & $\begin{array}{l}\text { Bortezomib } \\
\text { Carfilzomib } \\
\text { Ixazomib }\end{array}$ \\
\hline & Inibidores da tirosina cínase BCR-ABL & $\begin{array}{l}\text { Bosutinib } \\
\text { Dasatinib } \\
\text { Imatinib } \\
\text { Nilotinib } \\
\text { Ponatinib }\end{array}$ \\
\hline & Inibidor da tirosina cínase (multicínase) & Sorafenib \\
\hline & Inibidores da JAK1/2 & Ruxolitinib \\
\hline & \multirow{2}{*}{$\begin{array}{ll}\text { Inibidores da via } & \text { Inibidores de BTK } \\
\text { de sinalização do } & \\
\text { recetor da célula B } & \text { Inibidores da PI3K }\end{array}$} & $\begin{array}{l}\text { Acalabrutinib } \\
\text { Ibrutinib }\end{array}$ \\
\hline & & $\begin{array}{l}\text { Idelalisib } \\
\text { Buparlisib } \\
\text { Rigosertib } \\
\text { Duvelisib }\end{array}$ \\
\hline & Inibidores da histona desacetilase & $\begin{array}{l}\text { Panobinostat } \\
\text { Romidepsin } \\
\text { Vorinostat }\end{array}$ \\
\hline & Inibidores do BCL2 & Venetoclax \\
\hline & Inibidores m-TOR & Temsirolimus \\
\hline
\end{tabular}

a um ano após paragem dos fármacos).

Quando em monoterapia, recomenda-se a profilaxia contra a reativação HSVIVZV até 6 a 12 meses após paragem do tratamento. ${ }^{20}$

Nas terapêuticas de combinação (tais como: associação a outros agentes depletores de células $T$, associação a ciclofosfamida e associação pentostatina-anti-CD20) recomenda-se a profilaxia contra PPC até 6 a 12 meses após paragem do tratamento e contagem de CD4 superior a 200/ $\mathrm{mm}^{3} \cdot 20,31,32$

Em algumas terapêuticas mais intensivas (tais como a associação com anti-CD52 e metilprednisolona e a associação com anti-CD20, anti-CD52 e ciclosfosfamida) recomenda-se também a profilaxia contra as infeções fúngicas (fungos leveduriformes). ${ }^{20,29}$ 
Imunomoduladores (lenalidomida, pomalidomida e talidomida)

Principais infeções: bacterianas, VHB, VZV

A lenalidomida e a pomalidomida têm um efeito antitumoral direto por indução da apoptose tumoral, de inibição da angiogénese e imunomodulador.

A neutropenia é um efeito secundário (dose dependente) do tratamento com lenalidomida e pomalidomida, podendo atingir até $35 \%$ e $60 \%$ dos doentes tratados com um esquema que envolva lenalidomida e pomalidomida, respetivamente. Cerca de $1 / 3$ dos doentes com neutropenia desenvolve uma infeção grave, embora também seja frequente o aparecimento de infeções em doentes não neutropénicos. No caso da pomalidomida, o risco de infeção é superior nos primeiros três meses de terapêutica. No caso de infeção, o tratamento deverá ser suspenso, podendo ser recomeçado com uma dose mais baixa após resolução da infeção. ${ }^{45,46}$

Existem casos descritos na literatura (embora raros) de reativação de hepatite $\mathrm{B}$, mesmo em doentes com AgHBs negativo. Recomenda-se tratamento se AgHBs positivo e monitorização se AgHBs negativo e AcHBc positivo. ${ }^{47}$

Existe também o risco de reativação de VZV (especialmente se associado a outras terapêuticas imunossupressoras e idade avançada), pelo que se deve considerar profilaxia durante o período de quimioterapia ativa e neutropenia. $^{29}$

\section{Anti-CD20}

\section{Principais infeções: VHB}

CD20: fosfoproteína glicosilada presente na superfície de todas as células $B$, sendo a sua expressão progressivamente maior à medida que o linfócito $\mathrm{B}$ vai maturando; presente também nas neoplasias linfóides da série $B$, incluindo linfomas B não Hodgkin e LLC.

Pelo seu mecanismo de ação, os fármacos anti-CD20 causam uma depleção acentuada de linfócitos B (após a ligação do anticorpo há destruição dos linfócitos B por ação do complemento ou ação citotóxica dependente de anticorpos).

A utilização de fármacos anti-CD20 está relacionada com diminuição das imunoglobulinas séricas, pelo que deverão ser monitorizadas as imunoglobulinas séricas. No caso de infeções bacterianas de repetição e diminuição das imunoglobulinas séricas, pode-se ponderar reposição com imunoglobulina endovenosa (ev). ${ }^{48}$

O uso de fármacos anti-CD20 está relacionado com a reativação de $\mathrm{VHB}$, mesmo em doentes com AcHBc positivo e AgHBs negativo (por reativação do ADN circular fechado covalentemente presente nos hepatócitos). Assim, está indicado fazer profilaxia de reativação de $\mathrm{VHB}$ se $\mathrm{AcHBc}$ positivo (independentemente do AcHBs e AgHBs), com monitorização de PCR VHB mensal durante o tratamento e trimestral após conclusão do tratamento. A profilaxia deverá ser mantida pelo menos até 18 meses após paragem do tratamento. ${ }^{20,38,39}$

$\mathrm{Na}$ monoterapia com anti-CD20, não é necessária profilaxia de PPC ou VZV/HSV. Nas terapêuticas de combinação, podem-se ponderar estas profilaxias dependendo dos fármacos (por exemplo: combinação anti-CD20 com alta dose de corticóide). ${ }^{29}$

Existe também risco de reativação de leucoencefalopatia multifocal progressiva (LMP) entre 1 e 90 meses após a primeira dose, recomendando-se monitorização clínica.

\section{Anti-CD52}

\section{Principais infeções: PPC, HSV/VZV, CMV}

CD52: glicoproteína presente na grande maioria dos linfócitos e monócitos maduros, assim como na maioria das neoplasias linfóides (B e T); não se encontra presente nas células estaminais hematopoiéticas.

O anti-CD52 causa depleção linfocitária grave e prolongada (em alguns casos superior a um ano) na maioria dos doentes (a contagem mediana de $\mathrm{CD}^{+}$às quatro semanas de tratamento é de $0 / \mathrm{mm}^{3}$ e seis meses após paragem do fármaco de $238 / \mathrm{mm}^{3}$ ); causa também neutropenia profunda numa grande percentagem de doentes. ${ }^{1,49}$

Deverá ser sempre feita profilaxia contra PPC e reativação de HSVIVZV. Nestes casos a profilaxia deverá ser mantida até pelo menos dois meses após paragem do anti-CD52 e recuperação imunológica com contagem de CD4 superior a $200 / \mathrm{mm}^{3}{ }^{20}$

No caso de monoterapia com anti-CD52 pode-se optar por uma estratégia de antecipação anti-CMV (monitorização do PCR CMV semanal durante o tratamento e até pelo menos dois meses após paragem e reconstituição imunológica com contagem CD4 superior a $100 / \mathrm{mm}^{3}$ ). No caso de carga vírica positiva, pode-se optar por iniciar terapêutica ou monitorizar, dependendo da apresentação clínica, do valor da carga vírica e do projeto terapêutico (decisão caso a caso). ${ }^{20,29}$

No caso de tratamento de combinação entre anti-CD52 e outros quimioterápicos (especialmente no caso de vários depletores de células T como agentes alquilantes), pode-se ponderar profilaxia anti-CMV. ${ }^{29,37}$

Nos doentes com AcHBc positivo e AgHBs negativo, deverá ser monitorizada a carga vírica do VHB por PCR durante o tratamento com anti-CD52. Se carga vírica positiva deverá ser realizada profilaxia semelhante aos doentes com AgHBs positivo. ${ }^{38,39}$ Se carga vírica negativa, esta deverá ser monitorizada durante o período de imunossupressão. ${ }^{34}$

\section{Anti-CD30}

Principais infeções: bacterianas; LMP

CD30: expresso por células B e T ativadas (e não pelas células não ativadas); é um regulador positivo da apoptose, mas não se sabe qual a sua função ao certo; é um marcador dos linfomas de Hodgkin e do linfoma anaplásico de grandes células (linfoma T).

Após ligação do anti-CD30, há internalização do anticorpo por endocitose que leva à libertação do MMAE, que tem função antitumoral (agente antimitótico que bloqueia a polimerização do tubulina). 
Está associado a neutropenia grave prolongada e existe risco de reativação de LMP, pelo que se recomenda monitorização clínica.

Não estão recomendadas profilaxias. ${ }^{1,50}$

\section{Anti-CD19}

Principais infeções: infeções bacterianas, PPC, HSV/VZV, VHB

O CD19 é expresso pelos linfócitos B (exceto plasmócitos, incluindo células neoplásicas que derivam dos linfócitos $B$ ) e células dendríticas e é um dos co-recetores da célula B; faz parte na regulação da estimulação dependente de antigénio. Os anticorpos anti-CD19 provocam uma depleção de células $B$ e, consequentemente, hipogamaglobulinémia (mais profunda do que com anti-CD20). ${ }^{33}$ Para além disso, os anticorpos anti-CD19 fazem a ligação entre o CD3 nos linfócitos T e o CD19 nos linfócitos B, permitindo a ativação dos linfócitos $T$ contra as células $B$ malignas.

Nos ensaios clínicos, infeções graves como sépsis, pneumonia, bacteriemia e infeções oportunistas foram observados em cerca de $34 \%$ dos doentes tratados com anti-CD19, não parecendo estar associada com um aumento do risco de infeção comparando com a quimioterapia convencional. ${ }^{51}$

Devem ser monitorizadas as imunoglobulinas séricas e deve ser considerada terapêutica de substituição em caso de défice grave de lgG especialmente se infeções recorrentes. Apesar de haver poucos estudos clínicos, devido ao seu mecanismo de ação, recomendam-se as seguintes profilaxias:

-Profilaxia de HSVIVZV;

- Profilaxia de PPC;

- Tratamento de VHB e profilaxia em caso de AcHBc positivo (com agHBs positivo ou negativo). ${ }^{33}$

\section{Anti-CD22}

\section{Principais infeções: VZV}

CD22: glicoproteína transmembranar de função desconhecida, expresso nas células B maduras e nos blastos, mas não nas linhas não células $B$, incluindo nas células estaminais. ${ }^{52}$

Após ligação do anti-CD22 ao linfócito $B$, este é internalizado e induz destruição do ADN e morte celular por apoptose..$^{53}$

As terapêuticas com anti-CD22 não parecem aumentar significativamente o risco de infeção e, por isso, não se recomenda nenhuma profilaxia. ${ }^{34}$

\section{Anti-CD38}

\section{Principais infeções: VZV}

CD38: glicoproteína que se encontra nos linfócitos $B, T$ $\left(C D 4^{+}\right.$e $\left.C D 8^{+}\right)$e células NK; tem funções de regulação da homeostasia do cálcio intracelular, adesão celular e transdução de sinal; está sobrexpresso nas células do mieloma múltiplo.

O anticorpo liga-se ao CD38 e causa apoptose via citotoxicidade dependente de anticorpos ou complemento.
Está associado a reativação do VZV, pelo que se preconiza profilaxia contra reativação de VZV (iniciar 1 semana antes de começar anti-CD38 e continuar até três meses após paragem do anti-CD38). ${ }^{1,35}$

\section{Anti-SLAMF7}

Principais infeções: VZV, fúngicas

SLAMF7 (CD319): glicoproteína presente nas células NK e nas células do mieloma múltiplo.

O anti-SLAMF7 leva à destruição das células do mieloma múltiplo por citotoxicidade mediada por células (NK) dependente de anticorpos.

Existe um risco aumentado de infeção, especialmente de reativação de VZV com herpes zoster.

Preconiza-se profilaxia de VZV (duração: iniciar uma semana antes de começar anti-CD38 e continuar até três meses após paragem do anti-SLAMF7). Deverá também ser monitorizada a contagem total de linfócitos e subpopulações linfócitárias durante o tratamento. ${ }^{1,35}$

\section{Inibidores do proteossoma}

\section{Principais infeções: VZV}

Proteossoma: complexo enzimática celular que regula a homeostasia proteica dentro das células humanas.

A inibição do proteossoma leva à ativação de cascatas de sinalização que induzem apoptose das células tumorais e células $T$ ativada (interferência com imunidade mediada por células).

Terapêuticas com inibidor do proteossoma estão associadas com aumento do risco de reativação de VZV e de infeções respiratórias superiores. ${ }^{54}$

No caso de utilização de inibidores de proteossoma, deverá sempre ser feita profilaxia contra reativação VZV durante o período de quimioterapia ativa e de neutropenia e até quatro semanas após descontinuação. ${ }^{1}$

\section{Inibidores da tirosina cínase BCR-ABL \\ Principais infeções: VHB, VZV, HSV (baixa incidên- cia)}

Tirosina cínase BCR-ABL: produto genético da $t(9 ; 22)$ (cromossoma de Filadélfia, $\mathrm{Ph}+$ ) que leva a ativação crónica da tirosina cínase $\mathrm{ABL}$ pelo promotor do BCR causando divisão celular não controlada.

Os inibidores da tirosina cínase BCR-ABL bloqueiam o local ativo da tirosina cínase $B C R-A B L$, o que leva à diminuição da sua atividade e consequentemente maior controlo da divisão celular.

Apesar de relativamente específicos para o BCR-ABL, também inibem outras tirosina-cínases, sendo que o dasatinib inibe mais tirosina cínases que o imatinib. Provavelmente é a inibição destas outras tirosina cínases que aumenta o risco infecioso.

Provocam neutropenia, inibição da proliferação dos linfócitos $\mathrm{T} \mathrm{CD}^{+}{ }^{+}$e $\mathrm{CD} 8^{+}$e a resposta imune dos linfócitos $\mathrm{B}$. $\mathrm{O}$ risco de infeções encontra-se ligeiramente aumentado, embora possam existir infeções graves e fatais. O imatinib e o dasatinib inibem também a resposta específica $C D 8^{+}$ao 


\section{CMV e EBV. ${ }^{34}$}

Pelo risco de infeções estar apenas ligeiramente aumentado, não se recomenda nenhuma profilaxia nos doentes com inibidor do BCR-ABL, devendo-se manter vigilância clínica. ${ }^{3}$

\section{Inibidor da tirosina cínase (multicínase) \\ Principais infeções: bacterianas}

A inibição de várias cínases (incluindo por exemplo o VEGFR), leva à diminuição da angiogénese tumoral. No caso das neoplasias hematológicas, o sorafenib afeta também a transdução de sinal das células $T$ e a produção de interferão, inibindo e induzindo a apoptose das células $\mathrm{T}$ periféricas.

Embora o risco infecioso da utilização do sorafenib pareça ser negligenciável nos doentes com neoplasia de órgão sólido, no caso da LMA, por estar associado a quimioterapia convencional parece haver um risco aumentado de infeções bacterianas graves, possivelmente fatais.

Apesar do exposto anteriormente, não parece haver benefício na realização de profilaxias quando se administra sorafenib (atenção que como, até agora, só foi utilizado em associação à quimioterapia convencional da LMA devem aplicar-se as profilaxias indicadas nessa situação). ${ }^{3}$

\section{Inibidor do JAK 1/2}

\section{Principais infeções: HSV, VZV, LMP}

JAK 2: tirosina cínase que ativa a via JAK-STAT, que regula a transcrição genética.

Uma mutação ativadora da JAK2 (V617F) é o principal marcador da policitemia vera e também está presente na mielofibrose e trombocitémia essencial. A ativação da JAK2 leva à ativação constitutiva da STAT5 e STAT3, induzindo transformação maligna.

A sua inibição (inibidor da JAK 1 e 2) permite a inibição da via JAK-STAT que se encontra ativada.

Os inibidores da JAK1/2 provocam diminuição das células NK, alteração da função das células T por diminuição de produção de citocinas pro-inflamatórias e alteração da função e migração das células dendríticas.

A sua utilização está associada ao aumento considerável do número de infeções incluindo: pneumonia bacteriana, sépsis e choque séptico, PPC, reativação VZV, reativação de VHB (mesmo em doentes com AgHBs negativo e AcHBc positivo), toxoplasmose retiniana, criptococose, tuberculose e leucoencefalopatia multifocal progressiva. ${ }^{55}$ Existe evidência de reativação de CMV, mesmo fora do contexto de transplantação de progenitores hematopoiéti$\cos ^{36,56}$

Devido ao risco comprovadamente aumentado de infeções, aconselha-se profilaxia HSV/VZV, toxoplasmose e PPC, para além de tratamento de hepatite $B$ crónica e tuberculose latente. Nos doentes com AcHBc positivo e AgHBs negativo, recomenda-se monitorização de carga vírica de $\mathrm{VHB}$ com PCR e inicio de terapêutica se reativação. Apesar de haver ainda pouca evidência clínica, sugere-se também monitorização de reativação de CMV com PCR
CMV a cada três meses enquanto estiver sob tratamento com inibidor JAK1/2. ${ }^{34,36}$

\section{Inibidor do BTK}

Principais infeções: bacterianas, fúngicas

BTK: tirosina cínase essencial no desenvolvimento dos linfócitos B e ativação dos mastócitos.

A inibição da BTK impede a proliferação, induz apoptose das células $B$ (incluindo as células tumorais que sobre-expressam BTK) e impede a migração celular e adesão das células tumorais. Este inibidor não tem efeito tóxico nas células T normais. ${ }^{34}$

Apesar de haver pouca experiência clínica com estes inibidores, a mutação congénita do BTK já é conhecida (agamaglobulinemia de Bruton) o que pode ajudar a inferir o risco de infeções: aumento significativo das infeções bacterianas e encefalomielite crónica por enterovírus.

O uso clínico do inibidor do BTK parece estar associado com aumento significativo das infeções bacterianas (parece até ter uma incidência superior aos anti-CD20). Apesar disso, é difícil discernir o risco atribuível ao inibidor do BTK por ser usado em combinação em doentes com neoplasias de células $B$, já previamente tratados. ${ }^{34}$ Caso clínicos esporádicos publicados recentemente têm reportado aumento das infeções fúngicas como PPC, criptococose, histoplasmose, aspergilose e fusariose e casos de leucoencefalopatia multifocal progressiva. ${ }^{3,34}$ Tem também sido reportado na literatura vários casos de reativação de infeção VHB oculta e mesmo de reativação de infeção VHB passada, semelhante ao reportado com anti-CD20.40-42

Por haver ainda poucos estudos, aconselha-se vigilância clínica (incluindo monitorização das imunoglobulinas séricas) nos doentes sob inibidor do BTK e a seguinte profilaxia:

- Profilaxia de reativação de VHB se anticorpo HBc positivo (independentemente do AcHBs e AgHbs), com monitorização de PCR VHB a cada três meses. A profilaxia deverá ser mantida até 12 meses após paragem do tratamento..$^{40-42}$

- A profilaxia contra PPC pode ser ponderada, especialmente se fatores de risco adicionais de PPC (depletores de células T). ${ }^{34}$

- Recomenda-se monitorização de infeções fúngicas invasivas, não se recomenda para já profilaxia.

\section{Inibidores do fosfatidilinositol-3-cínase (PI3K) \\ Principais infeções: bacterianas, PPC}

PI3K é uma enzima presente nos linfócitos, mastócitos e neutrófilos, sendo um regulador da função e proliferação das células $B$.

Os inibidores do PI3K induzem apoptose e previnem a proliferação das células B por interrupção da via de sinalização que induz quimiotaxia e mantém a sobrevivência das células.

A sua utilização (em monoterapia ou em associação a anti-CD20) está associada ao aumento de infeções bacterianas pulmonares, de PPC e de reativação por CMV. 
Aconselha-se profilaxia de PPC durante o período de tratamento com inibidor do PI3K e até 2 - 6 meses após descontinuação do fármaco. ${ }^{20,34}$

Deverá ser realizada uma estratégia de antecipação anti-CMV (monitorização do PCR CMV semanal durante o tratamento). No caso de carga vírica positiva, pode-se optar por iniciar terapêutica ou monitorizar, dependendo da apresentação clínica, do valor da carga vírica e do projeto terapêutico (decisão caso a caso). ${ }^{34}$

\section{Inibidores da histona desacetilase \\ Principais infeções: bacterianas}

As histona desacetilases são enzimas responsáveis por remover um grupo acetil do aminoácido lisina nas histonas, permitindo que essas histonas se liguem mais firmemente ao ADN.

Desconhece-se para já qual é o mecanismo exato que leva ao efeito quimioterápico dos inibidores da histona desactilase, mas pensa-se estar relacionado com alterações epigenéticas

Embora existam para já poucos estudos, parece haver um ligeiro aumento das infeções bacterianas, especialmente pneumonias. ${ }^{57}$

Não estão recomendadas profilaxias.

\section{Inibidores do BCL2}

\section{Principais infeções: bacterianas}

O BCL2 é uma proteína regulatória apoptótica. Encontra-se sobre-expressa nas células da LLC, mediando a inibição apoptótica e a resistência à quimioterapia da LLC.

Os inibidores do BCL2 ligam-se diretamente ao BCL2 restaurando o processo de apoptose normal. Os inibidores do BCL2, em modelo animal, destroem seletivamente as células dendríticas (células apresentadoras de antigénios) e reduzem a produção de interferão alfa. ${ }^{34}$

Existe um risco aumentado de neutropenia e neutropenia febril, assim como pneumonias e infeções das vias respiratórias superiores. Infeções oportunistas como PPC, aspergilose invasiva ou toxoplasmose foram reportadas em baixa frequência (inferior a $4 \%$ ). ${ }^{34}$

Não estão recomendadas profilaxias, estando recomendada apenas vigilância clínica. ${ }^{58}$

\section{Inibidores do m-TOR}

\section{Principais infeções: PPC, HSV/VZV}

m-TOR: cínase que afeta o crescimento, proliferação, sobrevivência, metabolismo e organização citoesqueleto da célula.

A inibição do m-TOR permite a inibição de uma série de cascatas envolvidas na patogénese de muitas doenças

Tabela 3 - Quadro resumo da profilaxia a realizar durante a quimioterapia

\begin{tabular}{|c|c|c|c|c|c|c|c|}
\hline \multicolumn{2}{|c|}{ Terapêutica } & \multirow{2}{*}{$\begin{array}{l}\text { Antibacteriana } \\
\text { Não }\end{array}$} & \multirow{2}{*}{$\begin{array}{l}\text { Antifúngica } \\
\text { Não }\end{array}$} & \multirow{2}{*}{$\begin{array}{l}\text { Pneumocistose } \\
\text { Sim }\end{array}$} & \multirow{2}{*}{$\begin{array}{l}\text { HSV/VZV } \\
\text { Não }\end{array}$} & \multirow{2}{*}{$\begin{array}{l}\text { CMV } \\
\text { Não }\end{array}$} & \multirow{2}{*}{$\begin{array}{l}\text { VHB } \\
\text { Não }\end{array}$} \\
\hline \multirow{19}{*}{$\begin{array}{l}\frac{\pi}{0} \\
\frac{\pi}{0} \\
\frac{\pi}{0} \\
\frac{0}{0} \\
\frac{0}{2}\end{array}$} & Corticosteróides em alta dose & & & & & & \\
\hline & Agentes alquilantes & \multicolumn{6}{|c|}{ Sem profilaxias recomendadas } \\
\hline & Análogos das purinas & Não & Não & Não & Sim & Não & Não \\
\hline & Lena/ Pomalidomida & Não & Não & Não & Sim & Não & Não \\
\hline & Anti-CD20 & Não & Não & Não & Não & Não & Sim \\
\hline & Anti-CD52 & Não & Não & Sim & Sim & Sim & Não \\
\hline & Anti-CD30 & \multicolumn{6}{|c|}{ Sem profilaxias recomendadas } \\
\hline & Anti-CD19 & Não & Não & Sim & Sim & Não & Sim \\
\hline & Anti-CD22 & \multicolumn{6}{|c|}{ Sem profilaxias recomendadas } \\
\hline & Anti-CD38 & Não & Não & Não & Sim & Não & Não \\
\hline & Anti-SLAMF7 & Não & Não & Não & Sim & Não & Não \\
\hline & Inibidores do proteossoma & Não & Não & Não & Sim & Não & Não \\
\hline & Inibidor BCR-ABL & \multicolumn{6}{|c|}{ Sem profilaxias recomendadas } \\
\hline & Inibidor JAK1/2 & Não & Não & Sim & Sim & Sim & Não \\
\hline & Inibidor BTK & Não & Não & Sim & Não & Não & Sim \\
\hline & Inibidor do PI3K & Não & Não & Sim & Não & $\operatorname{Sim}$ & Não \\
\hline & Inibidor histona deacetilase & \multicolumn{6}{|c|}{ Sem profilaxias recomendadas } \\
\hline & Inibidor do BCL2 & \multicolumn{6}{|c|}{ Sem profilaxias recomendadas } \\
\hline & Inibidores do m-TOR & Não & Não & Sim & Sim & Não & Não \\
\hline \multirow{2}{*}{ 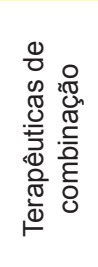 } & $\begin{array}{l}\text { Análogos das purinas } \\
\text { associado a outros agentes } \\
\text { deplores de células T, } \\
\text { ciclofosfamida ou anti-CD20 }\end{array}$ & Não & Não & Sim & Sim & Não & Não \\
\hline & $\begin{array}{l}\text { Análogos das purinas } \\
\text { associado a anti-CD52 e } \\
\text { corticoide }\end{array}$ & Não & Sim & Sim & Sim & Não & Não \\
\hline
\end{tabular}


malignas (neoplasias sólidas e hematológicas).

A sua utilização está claramente associada a aumento das infeções, incluindo infeções graves como PPC e reativação de HSVIVZV.

No caso de tratamento com inibidores de m-TOR (especialmente em tratamentos de associação de quimioterapia) deverá ser realizada profilaxia contra PPC e HSV/VZV. ${ }^{3}$

\section{Utilização de imunoglobulina endovenosa}

A imunoglobulina endovenosa poderá ser ponderada em:

- doentes com infeções bacterianas recorrentes (especialmente por bactérias capsuladas) e com diminuição das imunoglobulinas séricas (a LLC cursa frequentemente com hipogamaglobulinémia sérica e o mieloma múltiplo com hipogamaglobulinémia funcional) ${ }^{59-61}$;

- em doentes com infeção por parvovirus (diagnóstico por PCR);

- Dose: $400 \mathrm{mg} / \mathrm{kg}$ a cada 3 - 4 semanas, de modo a manter lgG superior a $500 \mathrm{mg} / \mathrm{dL} .{ }^{61}$

\section{Quadro resumo}

A realização de profilaxia durante a quimioterapia pode ser resumida na Tabela 3.

\section{SITUAÇÕES ESPECIAIS}

Estudo a ponderar em casos específicos, dependendo a história clínica e epidemiológica

Dependendo da história epidemiológica e de viagens, recomendamos que se tome em atenção em relação às seguintes infeções:

América do Norte

- Histoplasma capsulatum

América Central, do Sul e Caraíbas

- Histoplasma capsulatum

- Strongyloides stercoralis

- Schistosoma spp.

- Trypanosoma cruzi

- Leishmania spp.

Ásia

- Histoplasma capsulatum

- Strongyloides stercoralis

- Schistosoma spp.

- Leishmania spp.

África

- Histoplasma capsulatum

- Strongyloides stercoralis

- Schistosoma spp.

- Leishmania spp.

Erradicação prévia à quimioterapia em situações especiais

\section{Strongyloides stercoralis}

Devido à dificuldade de diagnóstico de infeção por Strongyloides stercoralis (serologia nos imunodeprimidos tem frequentemente falsos negativos e o diagnóstico para- sitológico é moroso e de baixa rentabilidade) e ao perfil de segurança dos antihelmínticos (especialmente da ivermectina), recomenda-se erradicação para todos os doentes com contexto epidemiológico que vão ser sujeitos a imunossupressão.

Tratamento: ivermectina 200 mg/kg/dia qd per os durante dias com repetição após duas semanas; Dose por peso: 15 - $24 \mathrm{~kg}-3 \mathrm{mg} ; 25$ - $35 \mathrm{~kg}-6 \mathrm{mg} ; 36$ - $50 \mathrm{~kg}$ - $9 \mathrm{mg} ; 51$ - $65 \mathrm{~kg}$ - $12 \mathrm{mg} ; 86$ - $79 \mathrm{~kg}-15 \mathrm{mg} ; \geq 80 \mathrm{~kg} 200 \mathrm{mg} / \mathrm{kg}$.

Alternativa: albendazol $400 \mathrm{mg}$ PO bid sete dias.

Quando iniciar quimioterapia: após erradicação. ${ }^{62-64}$

Nota: a ivermectina não se encontra à venda na farmácia de ambulatório, mas pode ser fornecida pela farmácia hospitalar

\section{Histoplasmose}

A quem fazer tratamento: serologia positiva e sem tratamento prévio.

Tratamento: itraconazol 200 mg/dia durante período de imunossupressão (a ser ponderado caso a caso). ${ }^{44,65}$

\section{Doenças de Chagas}

Se serologia positiva, deverá ser feita monitorização com PCR e ponderar tratamento se PCR positivo.

Tratamento: benznidazole 2,5 - 3,5 mg/kg PO bid 60 dias. ${ }^{66,67}$

\section{Schistossoma spp.}

A quem fazer tratamento: serologia positiva e sem tratamento prévio.

Tratamento: praziquantel $40 \mathrm{mg} / \mathrm{kg}$ PO dose única. ${ }^{55}$

\section{CONCLUSÃO}

A prevenção de infeção em doentes com neoplasia hematológica é complexa, quer pela patologia hematológica subjacente quer pela diversidade de fármacos utilizados. Para além disso, a literatura que existe sobre este tema encontra-se espalhada e não existe, no nosso conhecimento, nenhuma fonte bibliográfica que estabeleça a melhor forma de abordagem a estes doentes.

Por isso, parece-nos fundamental que se tente protocolar a abordagem a estes doentes, de uma forma simples e sistematizada, para que a prestação de cuidados a estes doentes ocorra com a maior minimização possível do risco infecioso. Para além disto, recomendam-se atualizações regulares do protocolo dada a multiplicidade de novos fármacos e a experiência que se vai acumulando com os mais recentes em uso clínico, que permite uma melhor documentação do risco de infeção.

\section{PROTECÇÃO DE PESSOAS E ANIMAIS}

Os autores declaram que os procedimentos seguidos estavam de acordo com os regulamentos estabelecidos pelos responsáveis da Comissão de Investigação Clínica e Ética e de acordo com a Declaração de Helsínquia da Associação Médica Mundial.

\section{CONFIDENCIALIDADE DOS DADOS}

Os autores declaram ter seguido os protocolos do seu centro de trabalho acerca da publicação de dados. 


\section{CONFLITOS DE INTERESSE}

Os autores declaram não terem qualquer conflito de interesse relativamente ao presente artigo.

\section{REFERÊNCIAS}

1. Singh D, Bonomo R. Infections in cancer patients. In: Hoag JB, editor. Oncology critical care: London: IntechOpen; 2016.

2. Centers for Disease Control and Prevention (CDC). Cancer Prevention and Control. [consultado 2017 dez 05]. Disponível em: https://www.cdc. gov/cancer/dcpc/about/index.htm.

3. Reinwald M, Boch T, Hofmann WK, Buchheidt D. Risk of infectious complications in hemato-oncological patients treated with kinase inhibitors. Biomark Insights. 2015;10:55-68.

4. Antunes A, Carvalho C, Gonçalves AF, Ferreira B, Ribeiro C, Santos $C$, et al. Manual de tuberculose e micobactérias não tuberculosas. In: Direção-Geral da Saúde: Programa Nacional para a Tuberculose. [consultado 2017 dez 05]. Disponível em: https://www.dgs.pt/ficheirosde-upload-2013/tb-manual-de-tuberculose-e-micobacterias-naotuberculosas-pdf.aspx.

5. Campino L, Maia C. Epidemiologia das leishmanioses em Portugal. Acta Med Port. 2010;23:859-64.

6. Leça A, Sarmento A, Freitas G, Marques J, Marques L, Santos L, et al. Programa Nacional de Vacinação 2017. In: Direção-Geral da Saúde. [consultado 2017 dez 05]. Disponível em: https://www.dgs.pt/ documentos-e-publicacoes/programa-nacional-de-vacinacao-2017-pdf. aspx

7. Direção-Geral da Saúde. Vacinação contra infeções por Streptococcus pneumoniae de grupos com risco acrescido para doença invasiva pneumocócica. [consultado 2017 dez 05]. Disponível em: https://www. dgs.pt/directrizes-da-dgs/normas-e-circulares-normativas/norma-n0112015-de-23062015-pdf.aspx.

8. Hibberd P. Immunizations in adults with cancer. In: Uptodate. [consultado 2017 dez 05]. Disponível em: https://www.uptodate.com/contents/ immunizations-in-adults-with-cancer/.

9. Abreu C, Sarmento A, Magro F. Screening, prophylaxis and counselling before the start of biological therapies: A practical approach focused on IBD patients. Dig Liver Dis. 2017:49:1289-97.

10. Chopra S, Lai M. Hepatitis A virus infection: prevention. In: Uptodate. [consultado $2017 \mathrm{dez}$ 05]. Disponível em: https://www.uptodate.com contents/hepatitis-a-virus-infection-treatment-and-prevention.

11. Teo E-K, Lok AS. Hepatitis B virus vaccination. In: Uptodate. [consultado 2017 dez 05]. Disponível em: https://www.uptodate.com/contents hepatitis-b-virus-immunization-in-adults

12. Centers for Disease Control and Prevention (CDC). Adult Immunization Schedule by Medical and Other Indications. [consultado 2017 dez 05] Disponível em: https://www.cdc.gov/vaccines/schedules/hcp/imz/adultconditions.html

13. Direcção Geral da Saúde. Vacinação contra Neisseria meningitidis do grupo $\mathrm{B}$ de grupos com risco acrescido para doença invasiva meningocócica. [consultado 2017 dez 05]. Disponível em: https://www. dgs.pt/directrizes-da-dgs/normas-e-circulares-normativas/norma-n0072016-de-09082016-pdf.aspx.

14. Di Sabatino A, Carsetti R, Corazza GR. Post-splenectomy and hyposplenic states. Lancet. 2011;378:86-97.

15. Davies JM, Lewis MP, Wimperis J, Rafi I, Ladhani S, Bolton-Maggs PH, et al. Review of guidelines for the prevention and treatment of infection in patients with an absent or dysfunctional spleen: prepared on behalf of the British Committee for Standards in Haematology by a working party of the Haemato-Oncology task force. Br J Haematol. 2011;155:308-17.

16. Cheng MP, Abou Chakra CN, Yansouni CP, Cnossen S, Shrier I, Menzies D, et al. Risk of active tuberculosis in patients with cancer: a systematic review and meta-analysis. Clin Infect Dis. 2017;64:635-44.

17. Menzies D. Diagnosis of latent tuberculosis infection (tuberculosis screening) in HIV-uninfected adults. In: Uptodate. [consultado 2017 dez 05]. Disponível em: https://www.uptodate.com/contents/approachto-diagnosis-of-latent-tuberculosis-infection-tuberculosis-screening-inadults.

18. Janier M, Hegyi V, Dupin N, Unemo M, Tiplica GS, Potocnik M, et al. 2014 European guideline on the management of syphilis. J Eur Acad Dermatol Venereol. 2014;28:1581-93

19. Wingard J. Prophylaxis of infection during chemotherapy-induced neutropenia in high-risk adults. In: UpToDate: UpToDate. [consultado 2018 apr 27]. Disponível em: https://www.uptodate.com/contents/

\section{FONTES DE FINANCIAMENTO}

Os autores declaram não ter recebido subsídios ou bolsas para a elaboração do artigo.

prophylaxis-of-infection-during-chemotherapy-induced-neutropenia-inhigh-risk-adults

20. Baden LR, Swaminathan S, Angarone M, Blouin G, Camins BC, Caspe $C$, et al. Prevention and treatment of cancer-related infections, Version 2.2016, NCCN Clinical Practice Guidelines in Oncology. J Natl Compr Canc Netw. 2016;14:882-913

21. Flowers CR, Seidenfeld J, Bow EJ, Karten C, Gleason C, Hawley DK et al. Antimicrobial prophylaxis and outpatient management of fever and neutropenia in adults treated for malignancy: American Society of Clinical Oncology clinical practice guideline. J Clin Oncol. 2013;31:794810

22. Imran $\mathrm{H}$, Tleyjeh IM, Arndt CA, Baddour LM, Erwin PJ, Tsigrelis C, et al. Fluoroquinolone prophylaxis in patients with neutropenia: a metaanalysis of randomized placebo-controlled trials. Eur J Clin Microbio Infect Dis. 2008;27:53-63.

23. Bow EJ. Fluoroquinolones, antimicrobial resistance and neutropenic cancer patients. Curr Opin Infect Dis. 2011;24:545-53.

24. Lingaratnam S, Thursky KA, Slavin MA. Fluoroquinolone prophylaxis: a word of caution. Leuk Lymphoma. 2011;52:5-6.

25. Kern WV, Klose K, Jellen-Ritter AS, Oethinger M, Bohnert J, Kern P, et al. Fluoroquinolone resistance of Escherichia coli at a cancer center: epidemiologic evolution and effects of discontinuing prophylactic fluoroquinolone use in neutropenic patients with leukemia. Eur J Clin Microbiol Infect Dis. 2005;24:111-8.

26. Hammond SP, Baden LR. Antibiotic prophylaxis during chemotherapyinduced neutropenia for patients with acute leukemia. Curr Hematol Malig Rep. 2007;2:97-103.

27. Siegel JD, Rhinehart E, Jackson M, Chiarello L, Health Care Infection Control Practices Advisory C. 2007 Guideline for Isolation Precautions: Preventing Transmission of Infectious Agents in Health Care Settings. Am J Infect Control. 2007;35:S65-164.

28. Wingard $\mathrm{J}$. Prophylaxis of invasive fungal infections in adults with hematologic malignancies. In: UpToDate. [consultado 2018 apr 29]. Disponível em: https://www.uptodate.com/contents/prophylaxis-ofinvasive-fungal-infections-in-adults-with-hematologic-malignancies.

29. Morrison V. Prevention of infections in patients with chronic lymphocytic leukemia. In: Uptodate. [consultado 2017 dez 05]. Disponível em: https://www.uptodate.com/contents/prevention-of-infections-in-patientswith-chronic-lymphocytic-leukemia.

30. Freifeld AG, Bow EJ, Sepkowitz KA, Boeckh MJ, Ito JI, Mullen CA et al. Clinical practice guideline for the use of antimicrobial agents in neutropenic patients with cancer: 2010 update by the infectious diseases society of america. Clin Infect Dis. 2011;52:e56-93.

31. Morrison VA, Rai KR, Peterson BL, Kolitz JE, Elias L, Appelbaum FR, et al. Impact of therapy With chlorambucil, fludarabine, or fludarabine plus chlorambucil on infections in patients with chronic lymphocytic leukemia: Intergroup Study Cancer and Leukemia Group B 9011. J Clin Oncol. 2001:19:3611-21.

32. Thomas CF, Limper AH. Treatment and prevention of Pneumocystis pneumonia in HIV-uninfected patients. In: Uptodate. [consultado 2017 dez 05]. Disponível em: https://www.uptodate.com/contents/treatmentand-prevention-of-pneumocystis-pneumonia-in-hiv-uninfected-patients.

33. Mikulska M, Lanini S, Gudiol C, Drgona L, Ippolito G, Fernández-Ruiz $M$, et al. ESCMID Study Group for Infections in Compromised Hosts (ESGICH) Consensus Document on the safety of targeted and biological therapies: an infectious diseases perspective (Agents targeting lymphoid cells surface antigens [I]: CD19, CD20 and CD52). Clin Microbiol Infect. 2018;pii:S1198-743X30151-4. (in press).

34. Reinwald M, Silva JT, Mueller NJ, Fortun J, Garzoni C, de Fijter JW, et al. ESCMID Study Group for Infections in Compromised Hosts (ESGICH) Consensus Document on the safety of targeted and biological therapies: an Infectious Diseases perspective (Intracellular signaling pathways: tyrosine kinase and mTOR inhibitors). Clin Microbiol Infect. 2018;pii:S1198-743X30182-4 (in press)

35. Lee HC, Weber DM. Advances and practical use of monoclonal antibodies in multiple myeloma therapy. Hematology Am Soc Hematol Educ Program. 2016;2016:512-20.

36. Heine A, Brossart $P$, Wolf $D$. Ruxolitinib is a potent immunosuppressive 
compound: is it time for anti-infective prophylaxis? Blood. 2013;122:38434.

37. O'Brien S, Ravandi F, Riehl T, Wierda W, Huang X, Tarrand J, et al. Valganciclovir prevents cytomegalovirus reactivation in patients receiving alemtuzumab-based therapy. Blood. 2008;111:1816-9.

38. Idilman R. Management of special patient groups with hepatitis B virus infection: the EASL 2017 Clinical Practice Guidelines. Turk J Gastroenterol. 2017;28:518-21.

39. European Association for the Study of the Liver. Electronic address eee, European Association for the Study of the L. EASL 2017 Clinical Practice Guidelines on the management of hepatitis B virus infection. J Hepatol. 2017;67:370-98.

40. Herishanu $Y$, Katchman $H$, PolliackA. Severe hepatitis B virus reactivation related to ibrutinib monotherapy. Ann Hematol. 2017;96:689-90.

41. Tedeschi A, Frustaci AM, Mazzucchelli M, Cairoli R, Montillo M. Is HBV prophylaxis required during CLL treatment with ibrutinib? Leuk Lymphoma. 2017;58:2966-8.

42. de Jesus Ngoma P, Kabamba B, Dahlqvist G, Sempoux C, Lanthier N, Shindano T, et al. Occult HBV reactivation induced by ibrutinib treatment: a case report. Acta Gastroenterol Belg. 2015;78:424-6.

43. Yue MC, Collins JT, Subramoniapillai E, Kennedy GA. Successful use of oseltamivir prophylaxis in managing a nosocomial outbreak of influenza A in a hematology and allogeneic stem cell transplant unit. Asia Pac J Clin Oncol. 2017;13:37-43.

44. Masur H, Brooks JT, Benson CA, Holmes KK, Pau AK, Kaplan JE, et al. Prevention and treatment of opportunistic infections in HIV-infected adults and adolescents: Updated Guidelines from the Centers for Disease Control and Prevention, National Institutes of Health, and HIV Medicine Association of the Infectious Diseases Society of America. Clin Infect Dis. 2014;58:1308-11.

45. Holstein SA, Jung SH, Richardson PG, Hofmeister CC, Hurd DD, Hassoun $\mathrm{H}$, et al. Updated analysis of CALGB (Alliance) 100104 assessing lenalidomide versus placebo maintenance after single autologous stem-cell transplantation for multiple myeloma: a randomised, double-blind, phase 3 trial. Lancet Haematol. 2017;4:e43142.

46. Bringhen S, De Wit E, Dimopoulos MA. New agents in multiple myeloma: an examination of safety profiles. Clin Lymphoma Myeloma Leuk. 2017; 17:391-407 e5.

47. Health Products Regulatory Agency. Lenalidomide (Revlimid) - Advice regarding viral reactivation. Dublin: HPRA; 2017.

48. Gea-Banacloche JC. Rituximab-associated infections. Semin Hematol. 2010;47:187-98.

49. Montillo M, Ricci F, Miqueleiz S, Tedeschi A, Morra E. Alemtuzumab in the treatment of fludarabine refractory B-cell chronic lymphocytic leukemia (CLL). Biologics. 2008;2:41-52.

50. Bradley AM, Devine M, DeRemer D. Brentuximab vedotin: an anti-CD30 antibody-drug conjugate. Am J Health Syst Pharm. 2013;70:589-97.

51. European Medicines Agency. Resumo das Características do Medicamento: Blincyto. [consultado 2017 dez 05]. Disponível em: http://ec.europa.eu/health/documents/communityregister/2017/20170918138730/anx_138730_pt.pdf.

52. Podhorecka M, Markowicz J, Szymczyk A, Pawlowski J. Target therapy in hematological malignances: new monoclonal antibodies. Int Sch Res Notices. 2014;2014:701493.

53. Morley NJ, Marks DI. Inotuzumab ozogamicin in the management of acute lymphoblastic leukaemia. Expert Rev Anticancer Ther.
2016;16:159-64.

54. Redelman-Sidi G, Michielin O, Cervera C, Ribi C, Aguado JM, Fernandez-Ruiz M, et al. ESCMID Study Group for Infections in Compromised Hosts (ESGICH) consensus document on the safety of targeted and biological therapies: an infectious diseases perspectiveimmune checkpoint inhibitors, cell adhesion inhibitors, sphingosine 1-phosphate receptor modulators and proteasome inhibitors. Clin Microbiol Infect. 2018; pii: S1198-743X30148-4 (in press).

55. Siqueira LD, Fontes DA, Aguilera CS, Timoteo TR, Angelos MA, Silva L, et al. Schistosomiasis: drugs used and treatment strategies. Acta Trop. 2017; 176:179-87.

56. von Hofsten J, Johnsson Forsberg M, Zetterberg M. Cytomegalovirus retinitis in a patient who received ruxolitinib. NEJM. 2016;374:296-7.

57. Roger T, Lugrin J, Le Roy D, Goy G, Mombelli M, Koessler T, et al. Histone deacetylase inhibitors impair innate immune responses to Tolllike receptor agonists and to infection. Blood. 2011;117:1205-17.

58. Huber H, Edenhofer S, Estenfelder S, Stilgenbauer S. Profile of venetoclax and its potential in the context of treatment of relapsed or refractory chronic lymphocytic leukemia. Onco Targets Ther. 2017; 10:645-56.

59. Casulo C, Maragulia J, Zelenetz AD. Incidence of hypogammaglobulinemia in patients receiving rituximab and the use of intravenous immunoglobulin for recurrent infections. Clin Lymphoma Myeloma Leuk. 2013;13:106-11.

60. Cooper N, Davies EG, Thrasher AJ. Repeated courses of rituximab for autoimmune cytopenias may precipitate profound hypogammaglobulinaemia requiring replacement intravenous immunoglobulin. Br J Haematol. 2009;146:120-2.

61. Silvergleid AJ, Ballow M. Overview of intravenous immune globulin (IVIG) therapy. In: Uptodate. [consultado 2017 dez 05]. Disponível em: https://www.uptodate.com/contents/overview-of-intravenous-immuneglobulin-ivig-therapy.

62. Center for International Blood and Marrow Transplant Research (CIBMTR); National Marrow Donor Program (NMDP); European Blood and Marrow Transplant Group (EBMT); American Society of Blood and Marrow Transplantation (ASBMT); Canadian Blood and Marrow Transplant Group (CBMTG); Infectious Disease Society of America (IDSA), et al. Guidelines for preventing infectious complications among hematopoietic cell transplant recipients: a global perspective. Bone Marrow Transplant. 2009;44:453-558.

63. Guerrero-Wooley R, Aranda-Aguirre E, Li W, Wilkin A, Palavecino E. Case report: strongyloides stercoralis hyperinfection in a patient with chronic lymphocytic leukemia. Am J Trop Med Hyg. 2017;97:1629-31.

64. Najmuddin A, Hadique S, Parker J. Strongyloides hyperinfection syndrome complications: a case report and review of the literature. W V Med J. 2012;108:32-8.

65. Hess J, Fondell A, Fustino N, Malik J, Rokes C. Presentation and treatment of histoplasmosis in pediatric oncology patients: case series and review of the literature. J Pediatr Hematol Oncol. 2017;39:137-40.

66. Pinazo MJ, Miranda B, Rodriguez-Villar C, Altclas J, Brunet Serra M, Garcia-Otero EC, et al. Recommendations for management of Chagas disease in organ and hematopoietic tissue transplantation programs in nonendemic areas. Transplant Ver. 2011;25:91-101.

67. Riganti J, Maqueda MG, Pinero MC, Volonteri VI, Galimberti RL. Reactivation of Chagas' disease: cutaneous manifestations in two immunosuppressed patients. Int J Dermatol. 2012;51:829-34. 